\title{
Patient aus Gambia mit sonografisch weißen Nieren - Fall 7 / 2016
}

Eva Aebert, Maike Büttner-Herold, Frederick Pfister, Thomas Mühlbacher, Christoph Berg, Martin Müller, Michael Haap, Ferruh Artunc

Im Ultraschall stellen sich die Nieren physiologischerweise echoarm dar. Echoreiche Veränderungen weisen auf verschiedene Erkrankungen hin. Im aktuellen „Tübinger Fall“ werden bei einem 39-jährigen Flüchtling aus Gambia sonografisch vollständig „schneeweiße“ Nieren entdeckt - ein seltener Befund. Die ausführliche Fallbeschreibung mit allen Details zum Patienten und den Untersuchungen, vielen Abbildungen und den Hintergründen finden Sie online.

\begin{abstract}
Anamnese I Ein 39-jähriger Mann aus Gambia hat Fieber $\left(38,4^{\circ} \mathrm{C}\right)$, Gliederschmerzen und Husten mit Auswurf. Sein Allgemeinzustand verschlechtert sich zusehends. Vier Monate zuvor ist er als Flüchtling nach Deutschland gekommen. Er spricht weder Deutsch, Englisch noch Französisch. Vorerkrankungen und Allergien sind nicht bekannt, Medikamente nimmt er derzeit keine.

- Herzfrequenz: 104/min

- Blutdruck:155/98 mmHg

- Atemfrequenz: $32 / \mathrm{min}$

Die Herztöne sind rein, die Atemgeräusche seitengleich vesikulär mit exspiratorischem Giemen. Ansonsten fallen bei der körperlichen Untersuchung abdominelle Anasarka und schmerzhaft geschwollene Knie mit tanzenden Patellae auf.
\end{abstract}

Labor I Zahlreiche Blutwerte sind pathologisch verändert. Die Befunde sprechen für ein Nierenversagen, eine Myokardschädigung sowie eine Sepsis. Die Urindiagnostik ergibt eine massive Proteinurie und renale Glukosurie.

Abdomen | Sonografisch stellen sich beide Nieren vollständig echoreich dar ( Abb. 1).

Thorax | Im EKG zeigen sich keine Ischämie-typischen Veränderungen. Echokardiografisch können Thromben und eine Endokarditis ausgeschlossen werden. Der linke Ventrikel ist deutlich hypertrophiert, bei mittelgradig eingeschränkter Pumpfunktion. Im Thorax-CT sind beidseitige Pleuraergüsse, ein Perikarderguss und Infiltrate im Mittellappen, subpleural und apikal zu sehen.

Erregerdiagnostik | In Blut- und Urinkulturen kann Staphylococcus aureus nachgewiesen werden. Die Virologie einer bronchoalveolären Lavage ist negativ, im Blut finden sich jedoch HIV-Antikörper. Die Infektion wird durch eine PCR bestätigt (148000 Kopien/ml, Norm:<40). Die Lymphozyten- und CD4-Helferzellzahl ist stark vermindert.

Verlauf I Der Patient leidet an einer S.-aureusSepsis unklarer Genese mit pulmonalen Streu-

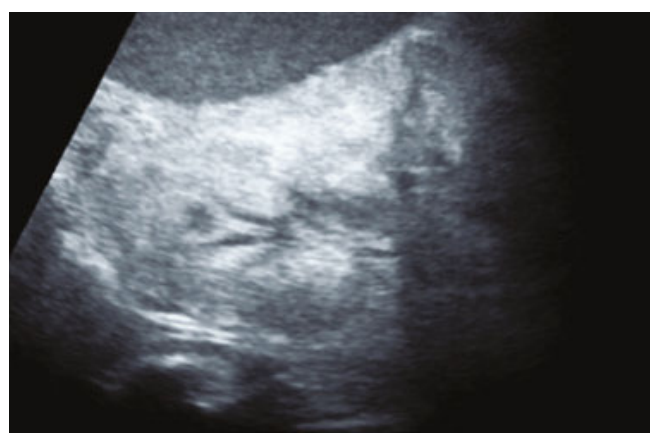

Abb. 1 Sonografie der rechten Niere: vollständig echoreicher („schneeweißer“) Kortex.

herden sowie einer HIV-Infektion und Nierenversagen. Er wird intensivmedizinisch antibiotisch und -mykotisch behandelt und dialysiert. Eine an die eingeschränkte Nierenfunktion angepasste antiretrovirale Therapie wird eingeleitet.

Nierenbiopsie I Im Verlauf bessert sich der Zustand des Patienten, er bleibt aber weiterhin dialysepflichtig. Aus diesem Grund wird eine Nierenbiopsie durchgeführt. Die Befunde sprechen für eine HIV-assoziierte Nephropathie (HIVAN).

HIVAN I Die HIVAN ist eine Spätmanifestation der HIV-Erkrankung. 90\% aller Patienten sind dunkelhäutig. Klinische Merkmale sind eine ausgeprägte Proteinurie und eine sich rasch verschlechternde Nierenfunktion. Werden die Patienten effektiv antiretroviral behandelt, ist die Überlebensrate ähnlich wie bei anderen Dialysepatienten. Im Einzelfall kann eine Nierentransplantation erwogen werden.

\section{Konsequenz für Klinik und Praxis}

- Bei unklarer Sepsis sollte eine HIV-Erkrankung in Betracht gezogen werden.

- Bei Patienten mit HIV können sonografisch „schneeweiße“ Nieren auf eine HIV-assoziierte Nephropathie (HIVAN) hinweisen.

- Eine HIVAN ist nicht reversibel und führt oft zur Dialysepflichtigkeit.

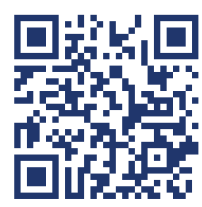

QR-Code einscannen und kompletten Fall online lesen oder unter: http://dx.doi.org/ 10.1055/s-0041-108031

\section{Korrespondenz}

Prof. Dr. med. Ferruh Artunc Innere Medizin IV, Sektion

Nieren- und Hochdruckkrankheiten, Universitätsklinikum Tübingen Ottfried-Müller-Str. 10

72076 Tübingen ferruh.artunc@med. uni-tuebingen.de

\section{Interessenkonflikt}

Die Autoren geben an, dass kein Interessenkonflikt besteht.

DOI 10.1055/s-0041-108031

Dtsch Med Wochenschr 2016; 141: 1243

(c) Georg Thieme Verlag KG . Stuttgart · New York . ISSN 0012-0472 